\title{
Minimizing Friction between Die and Punch using Ferro Fluids in Pressure Compaction of Metal Powder
}

\author{
Akshansh Mishra ${ }^{1}$, Anand Singh ${ }^{2}$ \\ ${ }^{1,2}$ Department of Mechanical Engineering SRM University Kattankulathur, Chennai, India
}

\begin{abstract}
Introduction: During the last twenty years powder metallurgy has progressed in many new directions; new types of products have been manufactured and new methods of manufacturing have been developed. One of those methods is Pressure Compaction method in which blended powders are pressed into shape in dies with help of punch. So there is friction exists between punch and die while carrying out this operation and hence in order to overcome that friction we are using Ferro fluids to prevent the damage occurred due to friction in Punch and die.
\end{abstract}

Keywords: Friction, die, punch, Ferrofluid, Alnico

\section{Introduction}

While carrying out the pressure compaction there is maximum chance of wear and tear between punch and die.

So in order to minimize the friction between them we are using ferro fluid. Ferro fluid is a colloidal suspension of single domain magnetic particles with typical dimension of about $10 \mathrm{~nm}$, dispersed in a liquid carrier. The liquid carrier can be polar or non-polar. Ferrofluids are optically isotropic but in the presence of external magnetic field exhibit induced birefringence. we can make our own Ferrofluid. For that we need laser jet tonner and vegetable oil. Then pour the tonner into the cup $(50 \mathrm{ml})$. Then pour two spoon of vegetable oil into the cup now stir it untill we get nice thin consistency. Now we can transfer it into small jar to make it easier for proper handling.

We have to apply the ferrofluid along the side of punch which is made up of magnetic material. Due to friction between die and punch temperature rise drastically. So we have to choose the magnetic material which can operate at high temperature range. So we have chosen ALNICO, which has high mechanical strength and high temperature stability.

Die material should be made up of non-ferrous material, so that it can not magnetised under the influence of ALNICO and hence process is carried out smoothly.

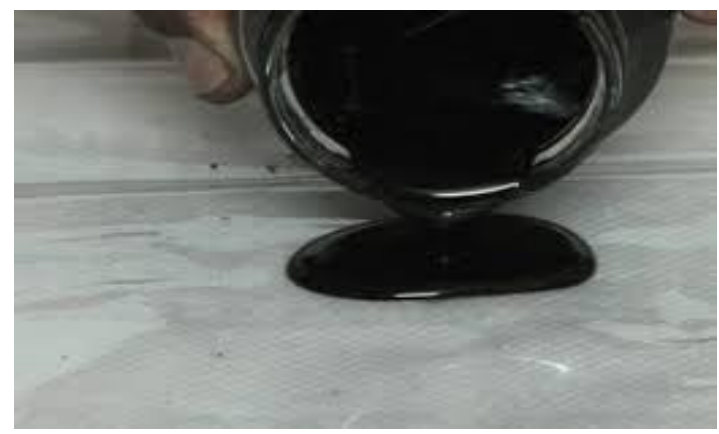

Figure 1.1: Ferrofluid obtained after mixing laser jet tonner and vegetable oil

\section{Apparatus}

Compaction process consists of equipment like upper punch, die, ejector, power feed shoe. The powder material is fed into the die with help of power feed shoe and hence compacted with help of punch. The compacted powder is ejected out of die with the help of ejector. The pressure require for pressing the metal powder ranges from $70 \mathrm{MPa}$ for Aluminium to $800 \mathrm{MPa}$ for high density iron parts. Because of the friction between the metal particles in the powder and the friction between punch and die wall, the density within the part can vary considerably. This variation can be minimized by proper punch and die design and by control of friction.

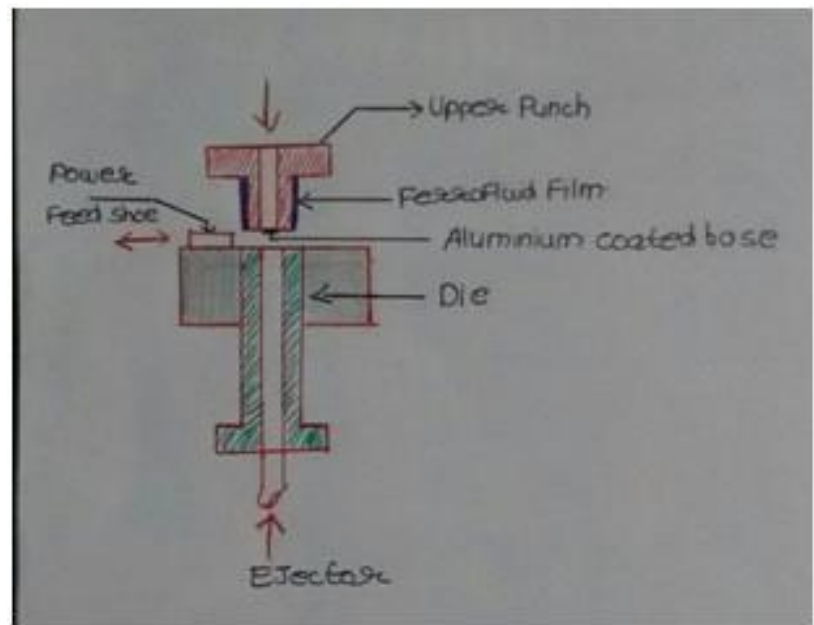

Figure 1.2: Arrangement of Pressure Compaction apparatus using ferrofluid

So we are using ferrofluid along the side of punch in order to overcome the friction. Ferrofluid possess the property of not spreading it remains adheres to ALNICO. Ferrofluid has replaced the use of oil as there is no chance of any leakage. We have further modified design of punch and die. As we have magnetised the opposite sides of punch so the base of punch have the chance of getting magnetised. Therefore it will attract the ferrous particles present in the powder and results uneven rough surface finishing, to overcome this problem we have coated the base of punch by non-ferrous material such as Aluminium which will not get magnetised. 


\section{International Journal of Science and Research (IJSR) \\ ISSN (Online): 2319-7064}

Index Copernicus Value (2013): 6.14 | Impact Factor (2014): 5.611

We have used non-ferrous as die material so we have taken Titanium as die material. Titanium has advantage of high strength to weight ratio. It's young's modulus is $116 \mathrm{GPa}$ which is relatively higher in comparison to other non-ferrous metal.

\section{Observation}

We have observed that die and punch life decreases drastically due to wear and tear due to friction.

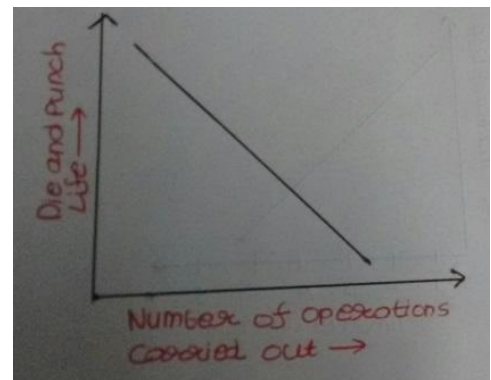

Figure 1.3: With use of Ferrofluid

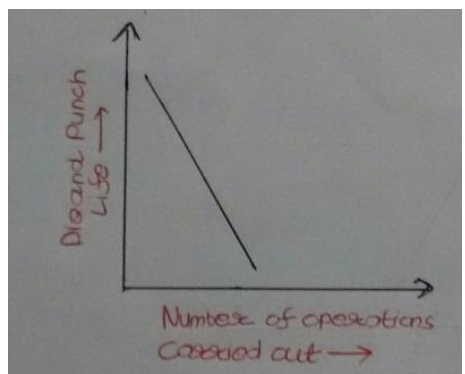

Figure 1.4: Without use of Ferrofluid

As the graph is plotted for the die and punch life versus number of operation carried out. From fig1.3 it is observed that the slope decreases slowly with the number of operation carried out and from fig1.4 we infer that the slop decreases gradually hence when we are using Ferrofluids the friction is minimized thus life of punch and die does not decreases drastically in comparison to the arrangement which does not uses ferrofluid.

\section{Conclusion}

We have drawn conclusion that by use of ferrofluids we can retard the risk of friction and thereby increasing the number of operations carried out during the process. The overall performance and efficiency of pressure compaction operation can be boosted by using Ferrofluid.

\section{References}

[1] Stefan Odenbach, "Ferrofluid: Magnetically Controllable Fluids and their applications". Springer Berlin Heidelberg, 26-Nov-2002

[2] Manufacturing Engineering and Technology SI $6^{\text {th }}$ Edition- SeropeKalpakjian and Steven R.Schmid

[3] Ferrofluid sketch model from "web.mit.edu" 